\title{
New Material and New Concepts Improve Hygroelectric Generator Output
}

\author{
Diana Lermen' ${ }^{1}$, Leandra P. dos Santos ${ }^{2}$, Fernando Galembeck ${ }^{1,2}$ \\ ${ }^{1}$ Institute of Chemistry, University of Campinas and ${ }^{2}$ Galembetech Consulting Ltd. \\ Campinas, Brazil \\ d264586@dac.unicamp.br; leandrapereiradossantos@gmail.com; \\ fernagal@unicamp.br
}

\section{Extended Abstract}

The energy harvesting from atmospheric humidity was first demonstrated in 2010 and named hygroelectricity (HE). A simple HE device is a pair of isolated metal sheets with different water ion adsorption capacities, forming self-charging, asymmetric capacitors [1][2]. The hygroelectric devices collect energy from the environment for dozens of days in an autonomous manner. Several research groups verified the possibility to collect energy from water moisture but often using graphene oxide [3] and various experimental arrangements, supported by different concepts and theoretical arguments, such as the moisture adsorption and diffusion processes. Nevertheless, the reported output power and voltage are still low, ranging from $10^{-8}$ to $10^{-3} \mathrm{~W}$ and $<0.5 \mathrm{~V}$, respectively [4].

Here, we present new scalable higroelectricity devices with unprecedented outputs, whose design guidelines follow new thermodynamic arguments valid for an open, multiphase, and non-electroneutral system. Thus, water ions adsorb on the electrodes following the Bronsted acid-basic properties of the surface: negative ions $\left(\mathrm{OH}^{-}\right)$adsorb in acidic oxide metal, and positive ions $\left(\mathrm{H}^{+}\right)$adsorb in base oxide metal. The ion partition at the electrodes creates an electric potential difference that increases each ion's electrochemical potential. And the potential gradients in the HE cell decrease the water-splitting reaction's non-spontaneity, releasing electric current from water. Using one electrode made out of exfoliated-andreassembled graphite coated Kraft paper $\left(56 \times 86 \mathrm{~cm}^{2}\right)$ while the other an aluminum sheet $\left(30 \times 94.5 \mathrm{~cm}^{2} ; 14\right.$ micrometers thick), we achieved a voltage output around $1.2 \mathrm{~V}$ and a $1.5 \mathrm{~mW}$ average power. Cell exposure outdoors showed a significant power output increase during the warmer hours due to the increased temperature and water vapor partial pressure. The new device presents many advantages: they use only inexpensive materials as well as simple and scalable fabrication processes. They are already suitable for some niche applications in distributed, autonomous energy microgeneration in remote environments. Foreseeable new developments may transform hygroelectricity into a competitive alternative for energy production in many settings since it uses only the ambient humidity and water ubiquitous on our planet with a low dependence of circadian factors.

\section{References}

[1] T. R. D. Ducati, L. H. Simoes, and F. Galembeck, "Charge partitioning at gas-solid interfaces: Humidity causes electricity buildup on metals," Langmuir, vol. 26, no. 17, pp. 13763-13766, 2010.

[2] K. S. Moreira, D. Lermen, L. P. dos Santos, F. Galembeck, and T. A. L. Burgo, "Flexible, low-cost and scalable, nanostructured conductive paper-based, efficient hygroelectric generator," Energy Environ. Sci., vol. 14, no. 1, pp. 353$358,2021$.

[3] F. Zhao, H. Cheng, Z. Zhang, L. Jiang, and L. Qu, "Direct Power Generation from a Graphene Oxide Film under Moisture," Adv. Mater., vol. 27, no. 29, pp. 4351-4357, 2015.

[4] D. Shen, W. W. Duley, P. Peng, M. Xiao, J. Feng, L. Liu, G. Zou and Y. N. Zhou, "Moisture-Enabled Electricity Generation: From Physics and Materials to Self-Powered Applications," Adv. Mater., vol. 32, no. 52, pp. 1-31, 2020. 